\title{
BY ADDITIVE ALGORITHM FOR DISPOSITION OF DANGEROUS GOODS ON CONTAINER SHIP
}

\section{ВИКОРИСТАННЯ АДИТИВНОГО АЛГОРИТМА ДЛЯ РОЗМЩЕННЯ НЕБЕЗПЕЧНИХ ВАНТАЖІВ НА КОНТЕЙНЕРНОМУ СУДНІ}

\author{
Kamienieva A., assistant professor, Kamieniev K., navigator \\ Камєнєва А.В., дочент, Камєнєв К. І., щ.д.n. \\ Національний університет «Одеська морська академія», Украӥна \\ National University «Odessa Maritime Academy», Ukraine
}

\begin{abstract}
High competition in container shipping industry reinforces the utter importance of safe, timely and sound cargo delivery. In order to ensure those qualities preliminary stowage planning that ensures vessels' seaworthiness components is a must. These include, among others, dangerous goods properties and compatibility. Nowadays stowage planning is done using stowage planning software. Although known programs do check dangerous goods stowage positions and compatibility they can't allocate containers automatically. Therefore, automation of the process is considered relevant.

To ensure safety when compiling a stowage plan human factors must be taken into account. Human errors are responsible for most cases of marine accidents, therefore solutions capable of mitigating them are required. Stowage planning software does that on the preliminary planning stage by calculating parameters responsible for seaworthiness, such as metacentric height (GM), sagging and hogging moments etc. While the parameters provide useful data for any ship's voyage planning, in container vessels' case they are also highly accurate. The reason for that is set container positions in vessels' holds, that allows to make accurate predictions of each unit's center of mass. It is noteworthy that all known stowage planning software is closed source so its algorithms can't be verified.

The article attempts to use a mathematical method for containers with dangerous goods allocation onboard of a ship. The attempt uses the additive algorithm to try and find allowable containers positions prior to loading. A mathematical model is built for dangerous goods stowage optimization.

Boolean programming methodology is applied to the problem. The usage simplifies calculations as all variables can only have two values: " 0 " or " 1 ". The algorithm is of branch and bound design paradigm and its calculations are limited by operations of addition and subtraction. The main idea consists of a systematic enumeration of possible candidate solutions, but the enumeration procedure allows to eliminate the solutions it can prove are not optimal.
\end{abstract}


The results received demonstrate the possibilities of using the method for preliminary stowage planning.

Keywords: dangerous goods, container ships, additive algorithm.

Постановка проблеми в загальному вигляді та їі зв'язок з важливими науковими та практичними задачами

Через велику конкуренцію на контейнерному флоті вимоги своєчасної, збереженої та безпечної доставки вантажів $є$ дуже важливими. Попереднє планування розміщення контейнерів на судні вимагає врахування багатьох параметрів, у тому числі характеристик небезпечних вантажів і їх сумісності. На сучасному флоті для складання вантажного плану зазвичай використовуються вантажні програми. Однак слід зазначити, що відомі вантажні програми не обчислюють положення небезпечних грузів самостійно, а лише перевіряють правильність заданого користувачем розміщення небезпечних вантажів. Тому автоматизація розміщення небезпечних вантажів на контейнерному судні представляється актуальною.

Аналіз останніх досягнень та публікацій, в яких розпочато розв`язування даної проблеми та висвітлювання нерозв язаних раніше частин загальної проблеми

Основним документом, який регламентує перевезення небезпечних вантажів морем, $є$ IMDG Code (International maritime dangerous goods code, Міжнародний кодекс морського перевезення небезпечних вантажів) [1].

Правила розміщення і сегрегації небезпечних вантажів наведені в розділі 7 «Положення, що стосуються транспортних операцій» Міжнародного кодексу морського перевезення небезпечних вантажів [1]. Небезпечні вантажі розділені на класи і підкласи. У таблиці 1 наведені 9 класів небезпечних вантажів.

Таблиия 1. Класи небезпечних вантажів згідно з кодексом IMDG

\begin{tabular}{|c|l|}
\hline $\begin{array}{c}\text { Номер } \\
\text { класу }\end{array}$ & \multicolumn{1}{|c|}{ Назва } \\
\hline Клас 1 & Вибухові матеріали \\
\hline Клас 2 & Гази \\
\hline Клас 3 & Легкозаймисті рідини \\
\hline Клас 4 & $\begin{array}{l}\text { Легкозаймисті тверді речовини; речовини, що можуть спонтанно запалитися, } \\
\text { речовини, що виділяють легкозаймисті гази при контакті з водою }\end{array}$ \\
\hline Клас 5 & Окислюючі речовини та органічні перекиси \\
\hline Клас 6 & Токсичні та інфекційні речовини \\
\hline Клас 7 & Радіоактивні матеріали \\
\hline Клас 8 & Корозійні субстанції \\
\hline Клас 9 & Різні небезпечні субстанції та предмети \\
\hline
\end{tabular}


Крім загальних вимог (Таблиця 2) при перевезеннях небезпечних вантажів, до контейнерних суден пред'являються додаткові вимоги. Вимоги до сегрегації на контейнерних судах представлені в кодексі в вигляді таблиць сегрегації і у вигляді малюнків [1].

Таблиия 2. Таблиия сегрегаиії небезпечних вантажів

\begin{tabular}{|c|c|c|c|c|c|c|c|c|c|c|c|c|c|c|c|c|c|}
\hline КлАС & $\mathbf{1 . 2}$ & $\mathbf{1 . 3}$ & $\mathbf{1 . 4}$ & $\mathbf{2 . 2}$ & $\mathbf{2 . 1}$ & $\mathbf{2 . 3}$ & $\mathbf{3}$ & $\mathbf{4 . 1}$ & $\mathbf{4 . 2}$ & $\mathbf{4 . 3}$ & $\mathbf{5 . 1}$ & $\mathbf{5 . 2}$ & $\mathbf{6 . 1}$ & $\mathbf{6 . 2}$ & $\mathbf{7}$ & $\mathbf{8}$ & $\mathbf{9}$ \\
\hline $\begin{array}{c}\mathbf{1 . 1 , 1 . 2} \\
\mathbf{1 . 5}\end{array}$ & $*$ & $*$ & $*$ & 2 & 4 & 2 & 4 & 4 & 4 & 4 & 4 & 4 & 2 & 4 & 2 & 4 & $\mathrm{X}$ \\
\hline $\begin{array}{c}\mathbf{1 . 3} \\
\mathbf{1 . 6}\end{array}$ & $*$ & $*$ & $*$ & 2 & 4 & 2 & 4 & 3 & 3 & 4 & 4 & 4 & 2 & 4 & 2 & 2 & $\mathrm{X}$ \\
\hline $\mathbf{1 . 4}$ & $*$ & $*$ & $*$ & 1 & 2 & 1 & 2 & 2 & 2 & 2 & 2 & 2 & $\mathrm{X}$ & 4 & 2 & 2 & $\mathrm{X}$ \\
\hline $\mathbf{2 . 1}$ & 4 & 4 & 2 & $\mathrm{X}$ & $\mathrm{X}$ & $\mathrm{X}$ & 2 & 1 & 2 & $\mathrm{X}$ & 2 & 2 & $\mathrm{X}$ & 4 & 2 & 1 & $\mathrm{X}$ \\
\hline $\mathbf{2 . 2}$ & 2 & 2 & 1 & $\mathrm{X}$ & $\mathrm{X}$ & $\mathrm{X}$ & 1 & $\mathrm{X}$ & 1 & $\mathrm{X}$ & $\mathrm{X}$ & 1 & $\mathrm{X}$ & 2 & 1 & $\mathrm{X}$ & $\mathrm{X}$ \\
\hline $\mathbf{2 . 3}$ & 2 & 2 & 1 & $\mathrm{X}$ & $\mathrm{X}$ & $\mathrm{X}$ & 2 & $\mathrm{X}$ & 2 & $\mathrm{X}$ & $\mathrm{X}$ & 2 & $\mathrm{X}$ & 2 & 1 & $\mathrm{X}$ & $\mathrm{X}$ \\
\hline $\mathbf{3}$ & 4 & 4 & 2 & 1 & 2 & 2 & $\mathrm{X}$ & $\mathrm{X}$ & 2 & 1 & 2 & 2 & $\mathrm{X}$ & 3 & 2 & $\mathrm{X}$ & $\mathrm{X}$ \\
\hline $\mathbf{4 . 1}$ & 4 & 3 & 2 & $\mathrm{X}$ & 1 & $\mathrm{X}$ & $\mathrm{X}$ & $\mathrm{X}$ & 1 & $\mathrm{X}$ & 1 & 2 & $\mathrm{X}$ & 3 & 2 & 1 & $\mathrm{X}$ \\
\hline $\mathbf{4 . 2}$ & 4 & 3 & 2 & 1 & 2 & 2 & 2 & 1 & $\mathrm{X}$ & 1 & 2 & 2 & 1 & 3 & 2 & 1 & $\mathrm{X}$ \\
\hline $\mathbf{4 . 3}$ & 4 & 4 & 2 & $\mathrm{X}$ & $\mathrm{X}$ & $\mathrm{X}$ & 1 & $\mathrm{X}$ & 1 & $\mathrm{X}$ & 2 & 2 & $\mathrm{X}$ & 2 & 2 & 1 & $\mathrm{X}$ \\
\hline $\mathbf{5 . 1}$ & 4 & 4 & 2 & $\mathrm{X}$ & 2 & $\mathrm{X}$ & 2 & 1 & 2 & 2 & $\mathrm{X}$ & 2 & 1 & 3 & 1 & 2 & $\mathrm{X}$ \\
\hline $\mathbf{5 . 2}$ & 4 & 4 & 2 & 1 & 2 & 2 & 2 & 2 & 2 & 2 & 2 & $\mathrm{X}$ & 1 & 3 & 2 & 2 & $\mathrm{X}$ \\
\hline $\mathbf{6 . 1}$ & 2 & 2 & $\mathrm{X}$ & $\mathrm{X}$ & $\mathrm{X}$ & $\mathrm{X}$ & $\mathrm{X}$ & $\mathrm{X}$ & 1 & $\mathrm{X}$ & 1 & 1 & $\mathrm{X}$ & 1 & $\mathrm{X}$ & $\mathrm{X}$ & $\mathrm{X}$ \\
\hline $\mathbf{6 . 2}$ & 4 & 4 & 4 & 2 & 4 & 2 & 3 & 3 & 3 & 2 & 3 & 3 & 1 & $\mathrm{X}$ & 3 & 3 & $\mathrm{X}$ \\
\hline $\mathbf{7}$ & 2 & 2 & 2 & 1 & 2 & 1 & 2 & 2 & 2 & 2 & 1 & 2 & $\mathrm{X}$ & 3 & $\mathrm{X}$ & 2 & $\mathrm{X}$ \\
\hline $\mathbf{8}$ & 4 & 2 & 2 & $\mathrm{X}$ & 1 & $\mathrm{X}$ & $\mathrm{X}$ & 1 & 1 & 1 & 2 & 2 & $\mathrm{X}$ & 3 & 2 & $\mathrm{X}$ & $\mathrm{X}$ \\
\hline $\mathbf{9}$ & $\mathrm{X}$ & $\mathrm{X}$ & $\mathrm{X}$ & $\mathrm{X}$ & $\mathrm{X}$ & $\mathrm{X}$ & $\mathrm{X}$ & $\mathrm{X}$ & $\mathrm{X}$ & $\mathrm{X}$ & $\mathrm{X}$ & $\mathrm{X}$ & $\mathrm{X}$ & $\mathrm{X}$ & $\mathrm{X}$ & $\mathrm{X}$ & $\mathrm{X}$ \\
\hline
\end{tabular}

Цифри і символи, зазначені у таблиці, мають таке значення:

1 - «на відстані від";

2 - «відокремлене від";

3 - «відділена цілим відсіком або трюмом від";

4 - «відділена продольно проміжним повним відсіком або трюмом від"; 
$\mathrm{X}$ - необхідно звіритися зі Списком небезпечних товарів;

* - необхідно звіритися 3 пунктом 7.2.7.1 для встановлення правил сегрегації між товарами класу 1.

При складанні вантажного плану повинен враховуватися людський фактор, тому на сучасному флоті для складання вантажного плану використовуються вантажні програми, які зменшують його вплив і тим самим підвищують безпеку судноплавства [2]. При експлуатації будь-якого судна вантажні програми грають самостійну роль, а в разі експлуатації контейнеровозів вони дозволяють отримати результати 3 більшою точністю. Точність обумовлена тим, що вантажні місця контейнеровозів чітко визначені, припущення про центр ваги дають мінімальні зміни результатів [3]. Слід зазначити, що всі відомі програми працюють за закритими алгоритмами.

\section{Формулювання мети статі (постановка задачі)}

У даній роботі зроблена спроба використання математичного методу (адитивного алгоритму) для знаходження допустимого варіанту розміщення небезпечних вантажів на контейнерному судні в процесі завантаження.

\section{Виклад матеріалу дослідження з обгрунтуванням отриманих наукових результатів}

Складемо математичну модель задачі оптимізації розміщення небезпечних вантажів на контейнерному судні. Позначимо через $x_{i j k}$ t контейнер виду $t 3$ вантажем класу $c$ в позиції $(i, j, k)$. Якщо контейнер знаходиться в позиції $(i, j, k)$, то відповідна змінна дорівнює 1 , в іншому випадку вона дорівнює 0.

Вид контейнера позначений змінною $t$, яка може приймати значення:

$t=\left\{\begin{array}{l}1-\text { відкритий }, \\ 2-\text { закритий } .\end{array}\right.$

Клас вантажу позначений змінною $c$. Змінна $c$ може приймати 18 різних значень: 1 - якщо клас вантажу 1.1 (Таблиця 2), 2 - якщо клас вантажу 1.2, .., 17 - якщо клас вантажу 9, 0 - якщо вантаж безпечний.

Таким чином,

$$
x_{i j k c t}=\left\{\begin{array}{l}
1, \text { якщо контейнер виду } t \text { з вантажем } \quad \text { класу } c \text { має позицію }(i, j, k), \\
0, \text { в іншому випадку. }
\end{array}\right.
$$

Нехай $N_{0}$ - число контейнерів з безпечними вантажами;

$N_{1}$ - число контейнерів з вантажами класу 1;

:

$N_{17}$ - число контейнерів з вантажами класу 17;

$N$ - загальне число контейнерів.

Тоді $N=\sum_{c=0}^{17} N_{c}$.

Розглянемо деякі обмеження:

- на загальне число контейнерів $-\sum_{i} \sum_{j} \sum_{k} \sum_{c} \sum_{t} x_{i j k c t}=N$; 
- на кількість контейнерів з безпечними вантажами $-\sum_{i} \sum_{j} \sum_{k} \sum_{t} x_{i j k 0 t}=N_{0}$;

- на кількість контейнерів з вантажами класу $1-\sum_{i} \sum_{j} \sum_{k} \sum_{t} x_{i j k 1 t}=N_{1}$;

$\cdots$

- на кількість контейнерів з вантажами класу $17-\sum_{i} \sum_{j} \sum_{k} \sum_{t} x_{i j k 17 t}=N_{17}$.

Обмеження на розміщення контейнерів розглянемо на прикладі.

Нехай в позиції $(i 0, j 0, k 0)$ знаходиться відкритий $(t=1)$ контейнер класу $4.1(c=8)$. Тогда $x_{i 0, j 0, k 0,8,1=1 .}$

Як витікає з Таблиці 2 для відкритих контейнерів 3 вантажем класу 1.1 $(« 4 »)$ :

$$
\begin{aligned}
& x_{i 0, j 0, k, 1,1}=0 \text { для } \forall k, \text { тобто } \sum_{k} x_{i 0, j 0, k, 1,1}=0,(t=1, c=1) \\
& x_{i, j 0, k 0,1,1}=0 \text { для } \forall i, \text { тобто } \sum_{i} x_{i, j 0, k 0,1,1}=0 .
\end{aligned}
$$

Обмеження для закритих $(t=2)$ контейнерів класу 1.1:

$$
\begin{aligned}
& x_{i 0, j 0, k, 1,2}=0 \text { для } \forall k, \text { тобто } \sum_{k} x_{i 0, j 0, k, 1,2}=0, \\
& x_{i, j 0, k 0,1,2}=0 \text { для } \forall i, \text { тобто } \sum_{i} x_{i, j 0, k 0,1,2}=0 .
\end{aligned}
$$

Аналогічні обмеження для всіх типів розміщення контейнерів згідно 3 таблицею 2 і всіх класів вантажів.

В основному, всі обмеження мають вигляд: якщо $x_{i 0, j 0, k 0, c 0, t 0}=1$, то сума певних змінних $x_{i j k}$ с дорівнює нулю. У вигляді нерівності ці обмеження виглядають так:

$$
\sum_{i j k c t} x_{i j k c t} \leq N\left(1-x_{i 0, j 0, k 0, c 0, t 0}\right) .
$$

Розглянуту в даній роботі задачу оптимізації можна віднести до окремого випадку задач цілочисельного лінійного програмування - булевському програмуванню, в якому змінні можуть приймати лише два значення - '0' i ' 1 '. Використання булевих змінних спрощує обчислювальні процедури (кожна змінна приймає всього лише 2 значення). Ця обставина враховується при розробці алгоритму вирішення задач з булевими змінними. У розглянутому алгоритмі обчислювальні операції обмежуються лише складанням i відніманням. Тому алгоритм вирішення задач 3 булевими змінними іноді називають адитивним алгоритмом. Цей алгоритм опирається на ідеї загального методу гілок і границь [4].

Для реалізації адитивного алгоритму оптимізаційна задача повинна мати такий вигляд.

Мінімізувати $z=\sum_{j=1}^{n} c_{j} x_{j}, \quad c_{j}>=0$

при обмеженнях 


$$
\sum_{j=1}^{n} a_{i j} x_{j}+S_{i}=b_{i}, i=1,2, . ., m
$$

$x_{j}=0$ або $1, j=1,2, . ., n, S_{i}>=0, i=1,2, . ., m$.

$S_{i}$ - додаткова змінна, асоційована з $i$-тим обмеженням.

Симплекс-таблиця даної задачі визначає допустиме рішення, коли всі $c_{j}>=0$ [4]. Якщо деякі значення $c_{j}<0$, задачу можна привести до необхідного виду за допомогою заміни $x_{j}=1-x_{j}$, де $x_{j}{ }^{\prime}$ булева змінна, в цільової функції i обмеженнях.

Основна ідея адитивного алгоритму полягає в переборі $2^{n}$ можливих рішень вихідної задачі. Процедура перебору здійснюється спеціальним чином, що дозволяє відкидати деякі рішення без безпосередньої перевірки. В кінцевому підсумку, реалізація адитивного алгоритму вимагає безпосереднього розгляду лише частини з $2^{n}$ можливих рішень.

У даній роботі зроблена спроба використовувати для розміщення небезпечних вантажів адитивний алгоритм [4]. Розглянуті вище обмеження на розміщення контейнерів, записані у вигляді нерівностей, приводяться до виду $\sum_{j=1}^{n} a_{i j} x_{j}+S_{i}=b_{i}$ введенням додаткової змінної $S_{i}$.

Скорочена схема роботи алгоритму наступна. На першому кроці всі початкові змінні покладаються рівними нулю. Отримане рішення виявляється неприпустимим, тому що деякі додаткові змінні $S_{i}$ набувають від'ємних значень. Тому деяким початковим змінним необхідно присвоїти значення 1. Далі здійснюється вибір однієї або декількох змінних 3 початкових, яким потрібно присвоїти значення 1. Метою цієї процедури є забезпечення допустимості рішення, тобто виконання умов $S_{i}>=0$ для всіх $i$. Зазначений вибір здійснюється за допомогою спеціальних тестів:

static public int testl(int[,] a, int [] si, int r)

$\{\ldots\}$

static public int test2(int $r$, int [] $c$, int zmin, int zsol)

$\{\ldots\}$

static public bool test3(int [,] a, int [] si, int [] nt)

$\{\ldots\}$

static public int test4(int[,] $a$, int [] xnt, int [] si)

$\{\ldots\}$

У тестовому прикладі розглядаються 13 контейнерів, серед яких два 3 небезпечним вантажем класу 4.1, розташовані в беї зазначеним на рис. 1 чином. Потрібно розмістити контейнер з вантажем класу 5.2. 


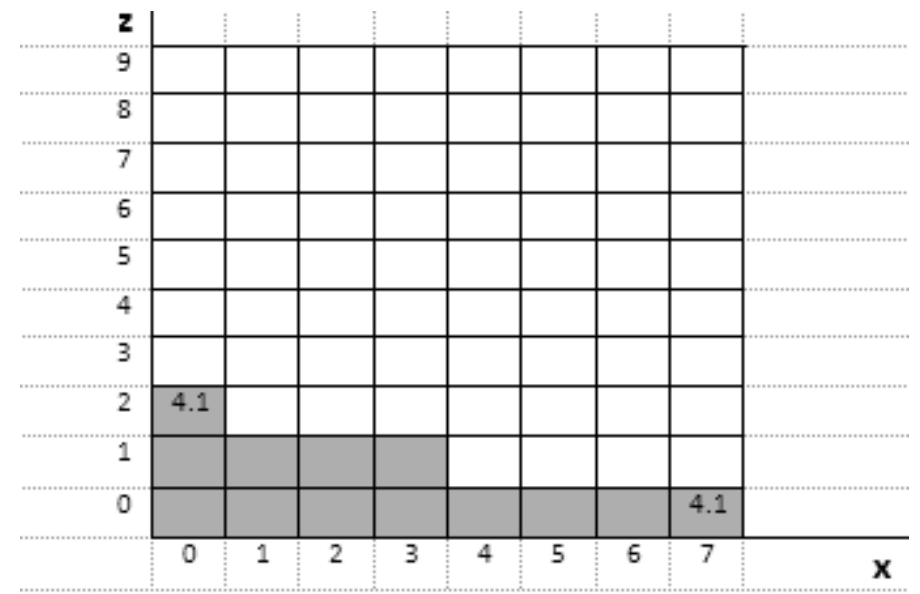

Рис. 1. Початкове розташування контейнерів в беї

Адитивний алгоритм реалізовано на об'єктно-орієнтованої мові програмування C \# (стандартизована як ECMA-334 і ISO / IEC 23270) [5]. Для тестового прикладу, розглянутого вище, цей алгоритм дає наступне рішення (Рис. 2):

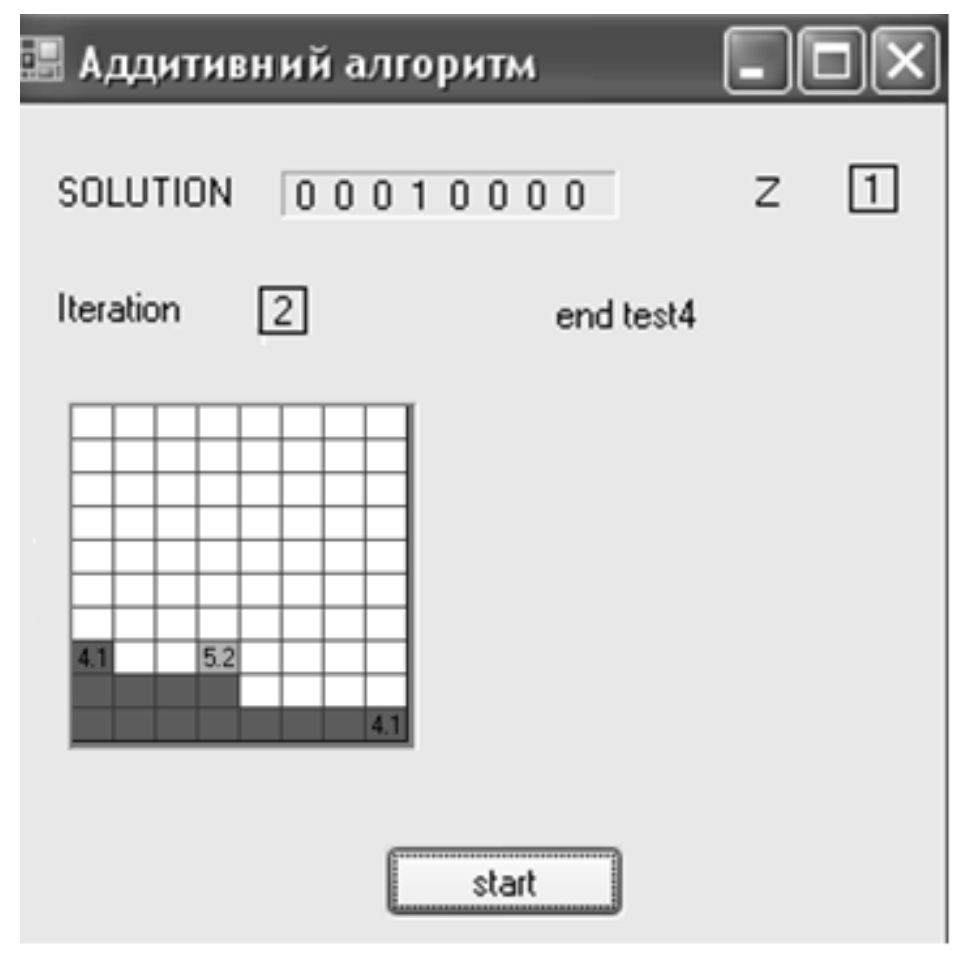

Рис. 2. Розміщення контейнера класу 5.2

\section{Висновки та перспектива подальшої роботи за даним напрямком}

Отримана математична модель засвідчила свою адекватність. Отримане за допомогою адитивного алгоритму розміщення контейнерів 3 небезпечними вантажами класів 4.1 та 5.2 (Рис. 2) є допустимим. Таким чином, вважаємо за доцільне продовжити удосконалення математичної моделі, а також дослідження використання адитивного алгоритму для розміщення небезпечних вантажів на контейнерних суднах. 


\section{ЛIТЕРАТУРА}

1. IMDG Code: Vol. 1 - CPI Group (UK) Ltd, Croydon, CR0 4YY, 2012. - 486 p.

2. Комплексный метод загрузки судна тарно-штучными грузами с учетом инерционных сил качки: автореф. / А. О. Чепок - Одесса: ОНМА, 2014. $22 \mathrm{c}$.

3. Перевозка опасных грузов: уч. пособ. / С. А. Кузнецов, Ю. А. Шумилов, А. Н. Давидчук, В. А. Халупенко, А. В. Халупенко. - Одесса: Издательство OHMA, 2006. $-32 \mathrm{c}$.

4. Введение в исследование операций: В 2-х книгах. Кн.1. / Х. Таха. - М.: Мир, 1985. - 479 с.

5. С\# 4.0 и платформа .NET 4 для профессионалов/ К. Нейгел, Б. Ивьен, Д. Глинн, К. Уотсон, М. Скиннер. - М.: Диалектика, Вильямс, 2011. $1440 \mathrm{c}$.

6. Закон України «Про перевезення небезпечних вантажів» станом на 20 лист. 2012 р. / http://zakon4.rada.gov.ua/laws/show/1644-14. 